Inhibition of Mycobacterium tuberculosis InhA: Design, synthesis and evaluation of new ditriclosan derivatives

Authors: Tom Armstrong, Malcolm Lamont, Alice Lanne, Luke J. Alderwick and Neil R. Thomas*

Author Information

Corresponding Author

Neil R. Thomas - Biodiscovery Institute, School of Chemistry, University of Nottingham, University Park, Nottingham, NG7 2RD, United Kingdom. Email: neil.thomas@nottingham.ac.uk

\author{
Authors \\ Tom Armstrong - Biodiscovery Institute, School of Chemistry, University of Nottingham, \\ University Park, Nottingham, NG7 2RD, United Kingdom. \\ Malcolm Lamont - Biodiscovery Institute, Department of Chemistry, University of Nottingham, \\ University Park, Nottingham, NG7 2RD, United Kingdom.
}

Alice Lanne - Institute of Microbiology and Infection, School of Bioscience, University of Birmingham, Birmingham, B15 2TT

Luke J. Alderwick - Institute of Microbiology and Infection, School of Bioscience, University of Birmingham, Birmingham, B15 2TT 


\begin{abstract}
Multi-drug resistant tuberculosis (MDR-TB) represents a growing problem for global healthcare systems. In addition to 1.3 million deaths in 2018, the World Health Organisation reported 484,000 new cases of MDR-TB. Isoniazid is a key anti-TB drug that inhibits InhA, a crucial enzyme in the cell wall biosynthesis pathway and identical in Mycobacterium tuberculosis and M. bovis. Isoniazid is a prodrug which requires activation by the enzyme KatG, mutations in KatG prevent activation and confer INH-resistance. 'Direct inhibitors' of InhA are attractive as they would circumvent the main clinically observed resistance mechanisms. A library of new 1,5 triazoles designed to mimic the structures of both triclosan molecules uniquely bound to InhA have been synthesised. The inhibitory activity of these compounds was evaluated using isolated enzyme assays with 2 (5-chloro-2-(4-(5-(((4-(4-chloro-2-hydroxyphenoxy)benzyl)oxy)methyl)-1H-1,2,3triazol-1-yl)phenoxy)phenol) exhibiting an $\mathrm{IC}_{50}$ of $5.6 \mu \mathrm{M}$. Whole-cell evaluation was also performed, with 11 (5-chloro-2-(4-(5-(((4-(cyclopropylmethoxy)benzyl)oxy)methyl)-1H-1,2,3triazol-1-yl)phenoxy)phenol) showing the greatest potency, with an $\mathrm{MIC}_{99}$ of $12.9 \mu \mathrm{M}$ against $M$. bovis.
\end{abstract}

\title{
Keywords
}

InhA, Triclosan, triazole, Isoniazid, Mycobacterium tuberculosis, TB 
Tuberculosis (TB) is one the leading global causes of mortality and is currently the world's deadliest infectious disease. In addition to the estimated 1.3 million deaths from TB in 2018, a further 0.25 million Human Immunodeficiency Virus-positive (HIV) individuals died as a result of co-infection with Mycobacterium tuberculosis. ${ }^{1}$

The current anti-TB treatment course relies on four drugs: isoniazid (INH), rifampicin (RIF), ethambutol (ETH) and pyrazinamide (PZA). The increasing prevalence of multi-drug resistant TB (MDR-TB) threatens to undermine the efficacy of this treatment regimen. MDR-TB infections are characterised as those displaying resistance to INH and RIF. In 2018, the WHO reported over 484,000 new MDR-TB infections. Additionally, 13,000 were classified as extensively drug resistant (XDR-TB) meaning they were also insensitive to any fluoroquinolone and at least one of the second-line injectable drugs. ${ }^{2-4}$ This emerging resistance is further exacerbated by the lack of novel drugs coming through the pipeline, with only three new drugs entering the clinic in the last 40 years (delamanid, pretomanid and bedaquiline). ${ }^{5,6}$

Mycobacteria's dense and complex cell wall represents one of the main reasons for the hardiness of the bacteria. The relative impermeability of the Mycobacterium cell wall can primarily be attributed to its mycolic acid component. This waxy layer consists of long chain $\left(\sim \mathrm{C}_{50-90}\right) \alpha-$ branched, $\beta$ hydroxylated fatty acids. This barrier not only hinders the passage of small molecules into the cell, but also provides protection from the host's immune response. ${ }^{7}$

The frontline drug INH elicits its biological effects through disruption of the mycolic acid biosynthetic pathway, via inhibition of the enzyme $\operatorname{InhA} .^{8} \operatorname{InhA}$ is a nicotinamide adenine 
dinucleotide (NADH)-dependent enoyl acyl carrier reductase which catalyses the chemoselective reduction of its 2-trans-enoyl-ACP substrate. The enzyme has an identical amino acid sequence (and hence structure) in M. tuberculosis and M. bovis, the main causative agents of tuberculosis in humans and dairy cattle respectively. INH is actually a pro-drug which requires activation before it can inhibit mycolic acid biosynthesis (Figure 1).

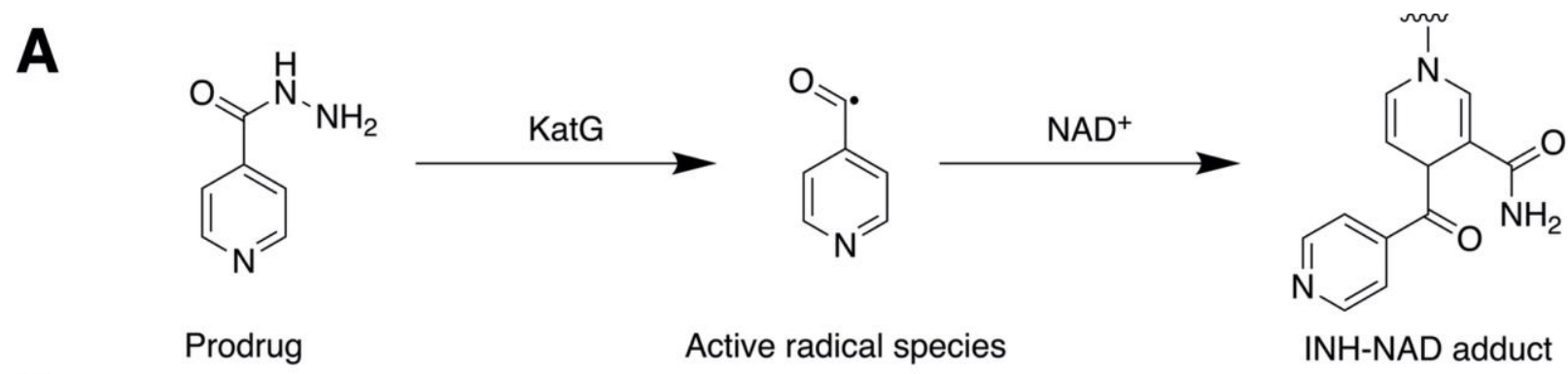

B

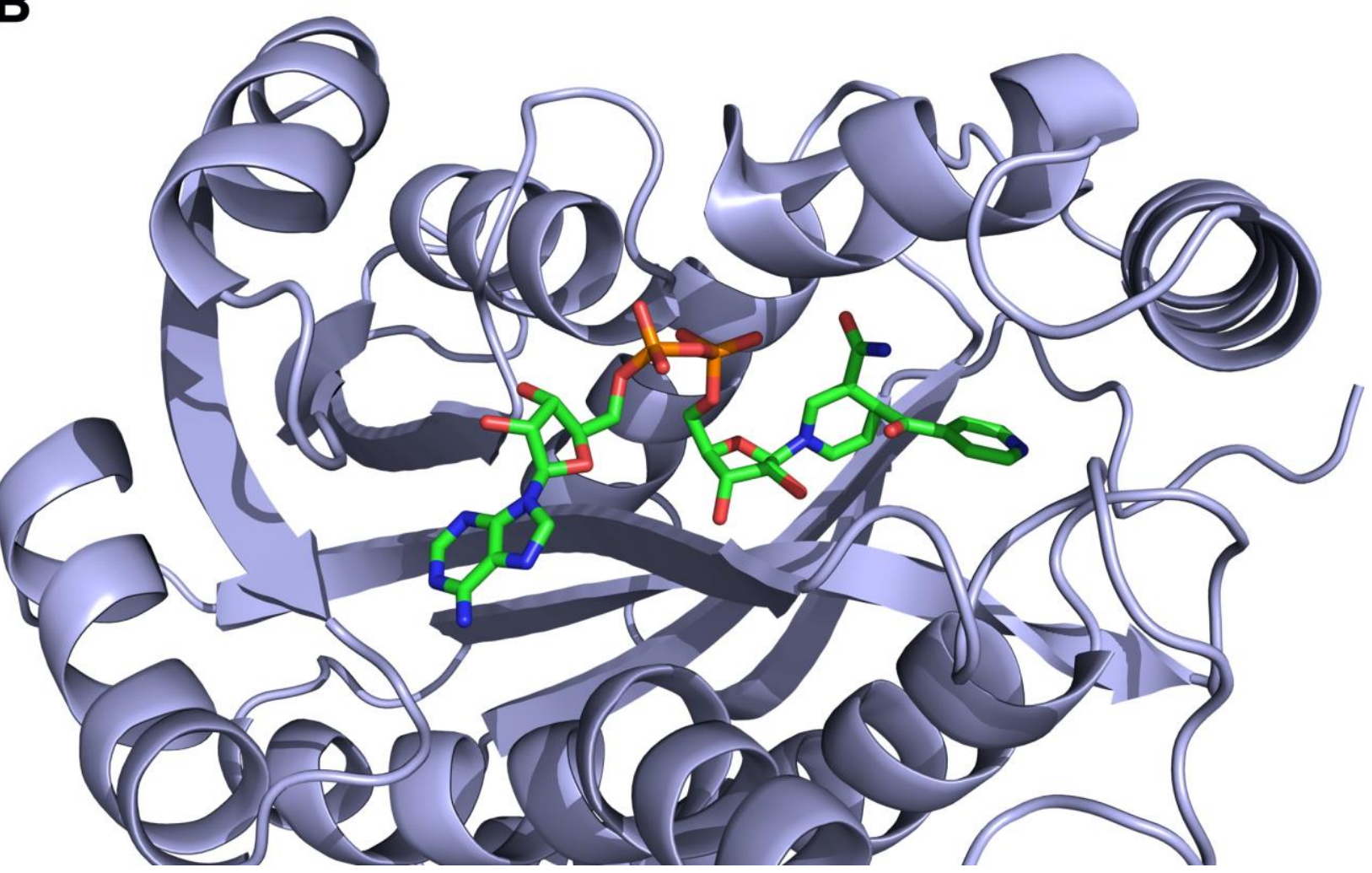

Figure 1. A) The structure of key anti-TB drug INH and the pathway through which it elicits its biological effects. B) Crystal structure of the INH-NAD adduct bound to InhA showing how the adduct blocks the substrate binding cavity (PDB: 1ZID). 
Initially, the catalase peroxidase enzyme, KatG converts INH to its corresponding isonicotinyl radical species. Upon activation, INH forms a covalent adduct with the co-factor which in-turn blocks the active site, preventing substrate binding. ${ }^{9}{ }^{10}$ A single KatG point mutation, $\mathrm{S} 315 \mathrm{~T}$, is sufficient to render INH inactive and has been implicated in up to $95 \%$ of INH resistant clinical isolates examined. ${ }^{11,12}$ With this in mind, the development of 'direct InhA inhibitors' represents a compelling approach for the discovery of new anti-TB drugs. ${ }^{13-16}$ Direct inhibitors refer to compounds which, unlike INH, do not require prior activation to exert their inhibitory effects. These inhibitors would circumvent the current resistance mechanisms and could be used to treat resistant infections. One such direct inhibitor is the small molecule, broad spectrum antibiotic triclosan (TCS, Figure 2.). TCS is a moderate, reversible inhibitor of InhA and has formed the basis of a number of studies using its scaffold in the development of more potent inhibitors. ${ }^{17,18}$

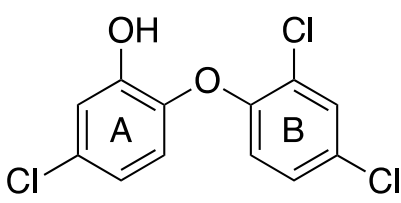

Figure 2. The structure of TCS and the denotation of the A and B rings.

Crystallographic studies have highlighted an unusual binding trait for the TCS:InhA complex. Two molecules of TCS are able to occupy the InhA active site (PDB: 1P45), something not replicated in homologous proteins from other bacteria. ${ }^{19}$ Inspection of the crystal structure reveals that the TCS2 molecule lies only $\sim 4.2 \AA$ away from the TCS1 moiety (Figure 3). This suggests that through modification of the B ring, it may be possible to obtain TCS-derivatives which are capable of occupying both binding sites through a single molecule, possibly producing a more potent and selective inhibitor for InhA that also benefits from a lower entropic cost in binding. 


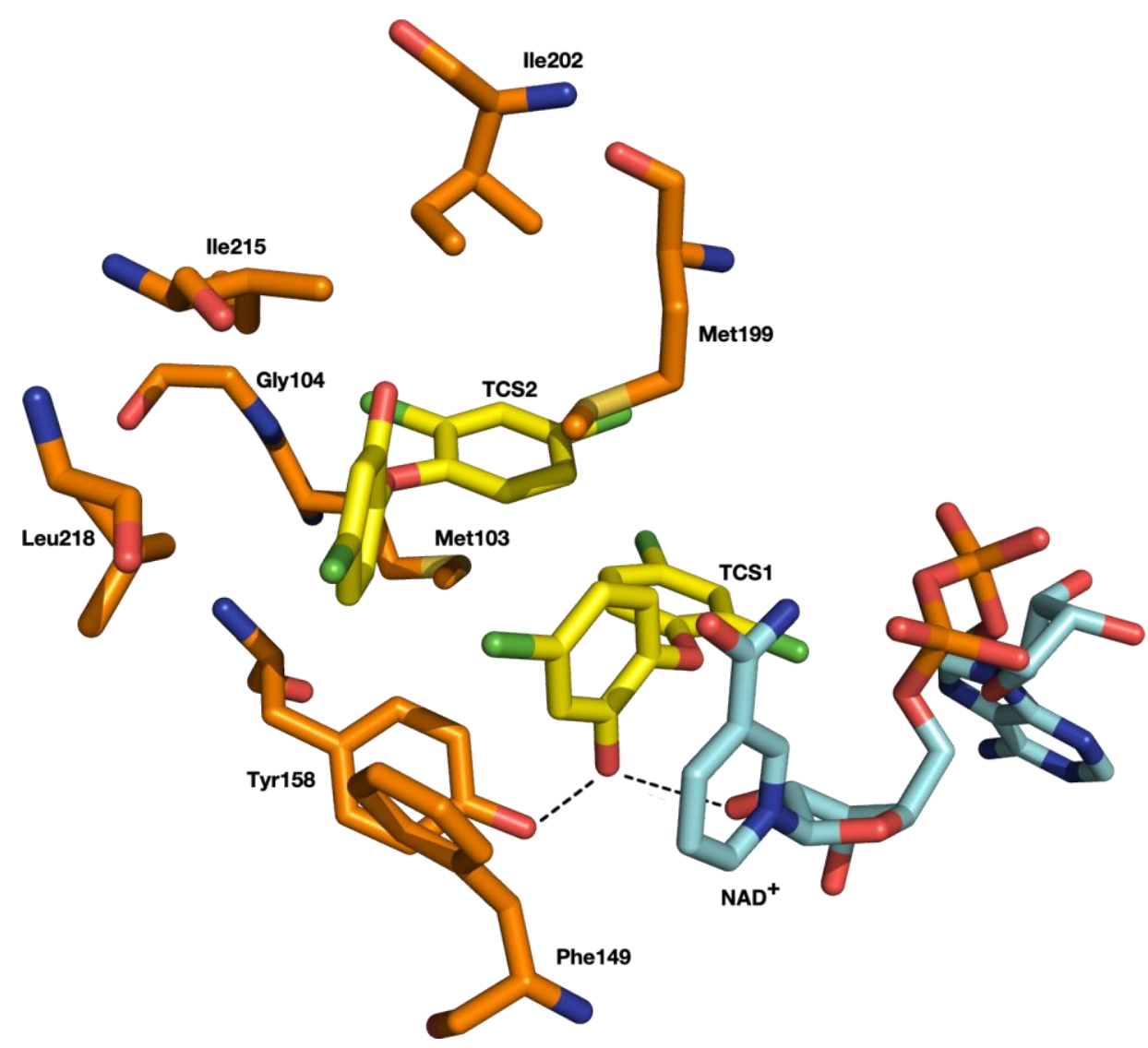

Figure 3. X-ray structure showing two TCS molecules bound to the InhA active site. Residues are shown with orange carbons, NAD ${ }^{+}$is shown with teal carbons, TCS are shown with yellow carbons. H-bonds are shown by dashed-black lines. (PDB: 1P45)

In this article, we report the in silico design, synthesis and characterization of a series of novel TCS derivatives bearing a 1,5-triazole group attached to the B-ring. These compounds were designed to occupy both of the TCS binding sites observed in the crystal structure. Biological evaluation was performed using an isolated InhA enzyme assay and whole-cell screening against M. bovis. 
The first step in designing TCS analogues which could anchor into both binding sites was identifying a suitable linker to connect the two fragments. It was vital that the linker did not disrupt the experimentally observed binding mode for TCS1, while at the same time the linker geometry had to direct the attached fragment back into the TCS2 binding region. To this end, it was thought that a disubstituted 1,2,3-triazole ring would be an appropriate motif. It was hoped that the rigid nature of the triazole scaffold would direct any substituent group back into the TCS2 binding site. This notion was explored using the Genetic Optimisation for Ligand Docking (GOLD) platform. ${ }^{20}$ Two test compounds, a 1,4 and a 1,5-triazole, were designed and both were docked into the InhA active site (PDB: 1P45). The binding poses obtained are shown below in Figure 4.

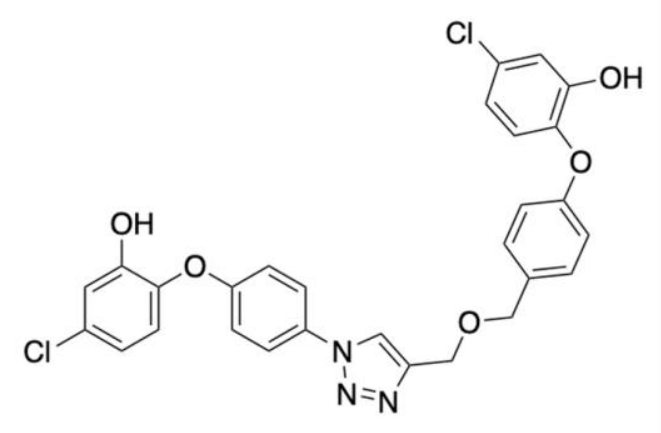

1

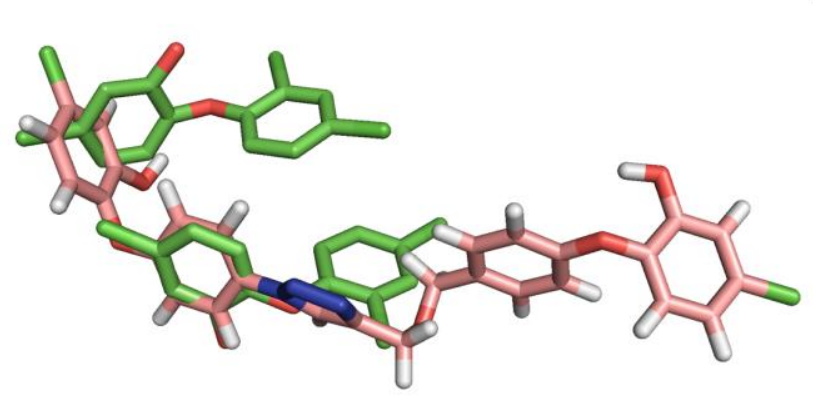

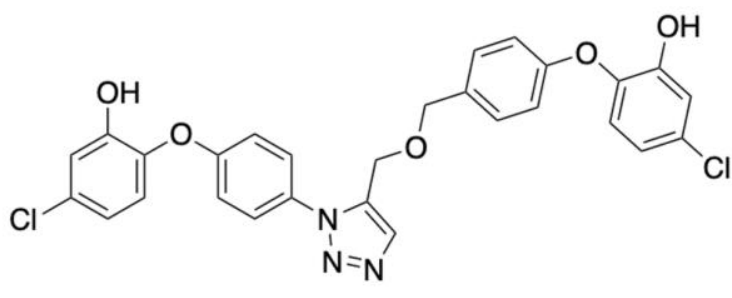

2

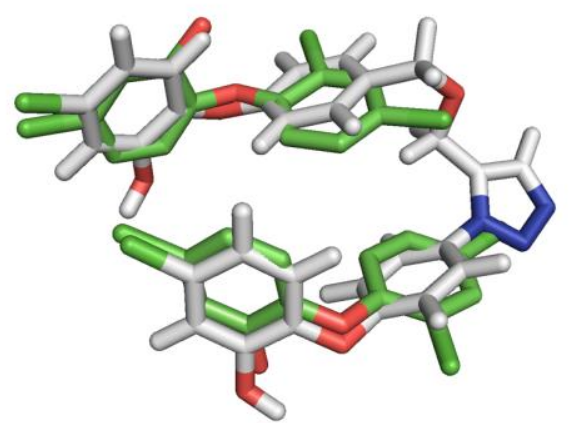

Figure 4. The structures of two basic TCS-triazole compounds and their docking poses generated by GOLD, this shows the overlap between the designed compounds and the two TCS moieties found in the active site. (PDB: 1P45) 
As demonstrated in Figure 4, when the two fragments are connected through a 1,5-triazole unit (2), the TCS-like binding mode is retained, and the secondary fragment occupies the same space as the TCS2 moiety. The 1,4-triazole (1) did not generate a suitable structure and the B-ring modification resulted in a perturbation of the TCS binding mode, including loss of the key hydrogen bonding network shown in Figure 3. This is of particular importance as this H-bonding network is conserved amongst most potent InhA inhibitors, with the exception of the methylthiazole compound class. ${ }^{19,21-23}$

With this information in hand, a range of compounds bearing a single aromatic ring attached through the 1,5-triazole motif were also designed (Figure 5). Previous studies have demonstrated that the B-ring $\mathrm{Cl}$ atoms are not required for potent InhA inhibition and so they were removed in an attempt to control the lipophilicity of the target compounds. ${ }^{18,24}$<smiles>[R7]c1ccc(COCc2cnnn2-c2ccc(Oc3ccc(Cl)cc3O)cc2)cc1</smiles>

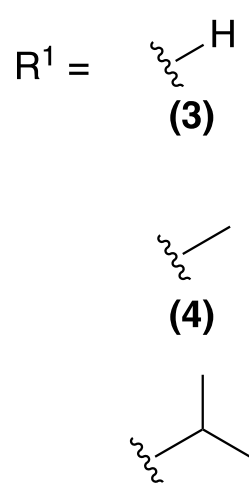

(5)

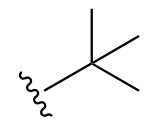

(6)<smiles>CO</smiles>

(7)<smiles>CCOC</smiles>

(8)<smiles>CCl</smiles>

(9)<smiles></smiles>

(10)

Figure 5. Design strategy for novel TCS-based InhA inhibitors 
<smiles>COc1cc(Cl)ccc1Oc1ccc(Cl)cc1Oc1ccc([N+](=O)[O-])cc1</smiles>

13

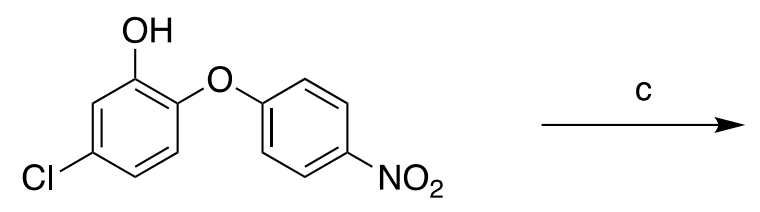

14<smiles>Nc1ccc(Oc2ccc(Cl)cc2O)cc1</smiles>

15<smiles></smiles>

16

Scheme 1. Reagents and conditions: a) $\mathrm{K}_{2} \mathrm{CO}_{3}, \mathrm{DMF}, 130^{\circ} \mathrm{C}, 18 \mathrm{~h}, 95 \%$; b) $\mathrm{BBr}_{3}, \mathrm{CH}_{2} \mathrm{Cl}_{2}, \mathrm{O}^{\circ} \mathrm{C}$ > r.t., $\mathrm{N}_{2}, 3 \mathrm{~h}, 89 \%$; c) $\mathrm{Zn}, \mathrm{NH}_{4} \mathrm{Cl}, \mathrm{MeOH}$, r.t., $18 \mathrm{~h}, 75 \%$; d) ${ }^{t} \mathrm{BuONO}, \mathrm{TMSN} 3, \mathrm{ACN}, 0{ }^{\circ} \mathrm{C}->$ r.t., $3 h, 80 \%$

The synthesis of biaryl azide $\mathbf{1 6}$ is shown in Scheme 1. The initial biaryl scaffold was assembled through an $\mathrm{S}_{\mathrm{N}} \mathrm{Ar}$ reaction using 1-fluoro-4-nitrobenzene and 4-chloro-2-methoxy phenol, furnishing 13 in near quantitative yields. Sequential $\mathrm{BBr}_{3}$ mediated ether demethylation and nitro reduction with $\mathrm{Zn} / \mathrm{NH}_{4} \mathrm{Cl}$ gave amine $\mathbf{1 5}$ in a good yield over two steps. Finally, functional group interconversion under the mild conditions first reported by Barral et al. provided the target azide. ${ }^{25}$ 
<smiles>COc1cc(Cl)ccc1Oc1ccc(C=O)cc1</smiles>

17<smiles>O=Cc1ccc(Oc2ccc(Cl)cc2O)cc1</smiles>

18

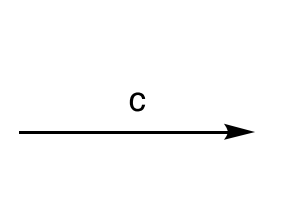<smiles>COc1cc(Cl)ccc1Oc1ccc(C=O)cc1</smiles>

19<smiles>COc1cc(Cl)ccc1Oc1ccc(CO)cc1</smiles>

20

21<smiles>C#CCOCc1ccc(Oc2ccc(Cl)cc2O)cc1</smiles>

22

Scheme 2. Reagents and conditions: a) $\mathrm{K}_{2} \mathrm{CO}_{3}, \mathrm{DMF}, 130^{\circ} \mathrm{C}, 18 \mathrm{~h}, 92 \%$; b) $\mathrm{AcOH}, \mathrm{HBr}, 140{ }^{\circ} \mathrm{C}$, $18 \mathrm{~h}, 38 \%$; c) $\mathrm{MOMCl}$, DIPEA, $\mathrm{CH}_{2} \mathrm{Cl}_{2}$, r.t., $18 \mathrm{~h}, 86 \%$; d) $\mathrm{NaBH}_{4}, \mathrm{MeOH}, 0^{\circ} \mathrm{C}->$ r.t., 4 h, quant.; e) $\mathrm{NaH}$, propargyl bromide, $\mathrm{DMF}, \mathrm{O}^{\circ} \mathrm{C}$-> r.t., $18 \mathrm{~h}, 79 \%$; f) $6 \mathrm{M} \mathrm{HCl}(\mathrm{aq}), \mathrm{MeOH}, 70^{\circ} \mathrm{C}, 2 \mathrm{~h}$, $90 \%$

The synthesis of alkyne-bearing TCS fragment 22 is shown in Scheme 2. The biphenyl scaffold 17 was assembled in a similar fashion to the corresponding nitro-compound $\mathbf{1 3}$, in a good yield. Cleavage of the methyl ether was performed using $\mathrm{AcOH}$ and $\mathrm{HBr}$ at elevated temperatures, generating 18 in a modest yield. This method was used due to the instability of the benzaldehyde 
group that was observed when demethylation was attempted with $\mathrm{BBr}_{3}$. The newly exposed phenol was then reprotected using $\mathrm{MOMCl}$ in a good yield. Benzaldehyde 19 was reduced to its corresponding benzyl alcohol using $\mathrm{NaBH}_{4}$ before etherification using $\mathrm{NaH}$ and propargyl bromide, giving ether $\mathbf{2 1}$ in good yield over two steps. The phenol functionality was then unmasked using $6 \mathrm{M} \mathrm{HCl}$ to furnish the alkyne-bearing TCS fragment 22 in a near quantitative yield.

Selective formation of 1,5-triazoles can be achieved through the use of ruthenium catalysed azidealkyne cycloaddition (RuAAC) and has seen increasing numbers of examples in the literature over the last decade. ${ }^{26,27}$ With $\mathbf{2 2}$ and $\mathbf{1 6}$ in hand, the 1,5-triazole motif was assembled via an RuACC, using $\mathrm{Cp} * \mathrm{RuCl}\left(\mathrm{PPh}_{3}\right)_{2}$ in 1,4-dioxane (Scheme 3).

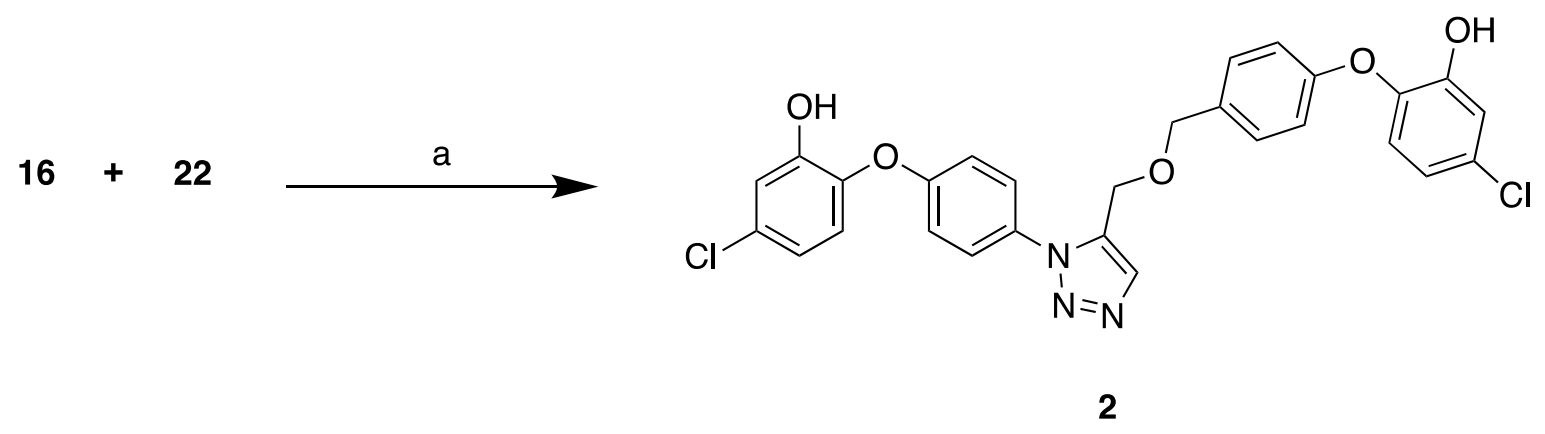

Scheme 3. Reagents and conditions: a) $\mathrm{Cp} * \mathrm{RuCl}\left(\mathrm{PPh}_{3}\right)_{2}, 1,4$-dioxane, $60^{\circ} \mathrm{C}, \mathrm{N}_{2}, 18 \mathrm{~h}, 17 \%$

The RuAAC reaction furnished $\mathbf{2}$ in an acceptable yield, following reverse phase high performance liquid chromatography (HPLC) purification. The identity of the product was confirmed as a 1,5 triazole using the NMR methods previously discussed by Creary et al. ${ }^{28}$ Following the synthesis of $\mathbf{2}$, the aforementioned truncated analogues were synthesised from the azide $\mathbf{1 6}$ and alkyne 
fragments (23-32, synthesis detailed in supplementary information), using the same RuAAC conditions, giving the desired 1,5-triazoles in moderate yields after HPLC (Scheme 4).

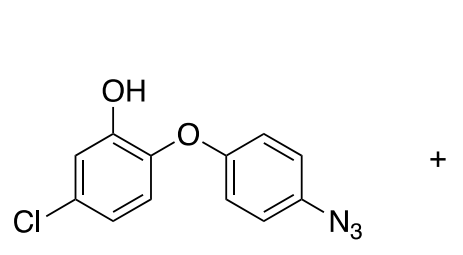

16

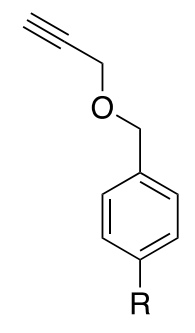

$23-32$
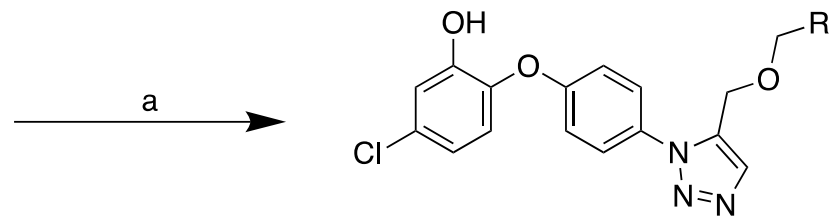

3-12

Scheme 4. Reagents and conditions: a) $\mathrm{Cp} * \mathrm{RuCl}\left(\mathrm{PPh}_{3}\right)_{2}, 1,4$-dioxane, $60^{\circ} \mathrm{C}, \mathrm{N}_{2}, 18 \mathrm{~h}, 5-33 \%$

An isolated enzyme assay was used to assess the inhibitory properties of the compounds synthesised. Initial screening was performed at $50 \mu \mathrm{M}$ with $150 \mathrm{nM}$ of InhA from M. tuberculosis using a standard UV absorbance assay that has been widely used in the identification of novel InhA inhibitors. Assays were performed using 2-trans-octenoyl CoA as a mimic for the enzyme's natural substrate. ${ }^{29}$ All compounds evaluated were of above $90 \%$ purity as determined by analytical HPLC. 
Table 1. Inhibitory data for compounds tested using an isolated enzyme assay, conducted at 50 $\mu M$. GOLD fitness scores are also included for each compound. Inhibition values are an average of duplicate assays.

\begin{tabular}{ccc}
\hline Compound & GOLD Fitness Score & Inhibition $/ \%$ \\
\hline $\mathbf{2}$ & 87.7 & 100 \\
$\mathbf{3}$ & 65.2 & 12 \\
$\mathbf{4}$ & 73.5 & 38 \\
$\mathbf{5}$ & 77.8 & 72 \\
$\mathbf{6}$ & 74.0 & 6 \\
$\mathbf{7}$ & 69.0 & 13 \\
$\mathbf{8}$ & 76.7 & 44 \\
$\mathbf{9}$ & 73.2 & 0 \\
$\mathbf{1 0}$ & 75.6 & 47 \\
$\mathbf{1 1}$ & 80.7 & 11 \\
$\mathbf{1 2}$ & 83.6 & 42 \\
$\mathbf{T C S}$ & 70.8 & 92 \\
\hline
\end{tabular}

The inhibitory activity observed for compounds $\mathbf{2}-\mathbf{1 2}$ is summarized in Table $\mathbf{1}$, these results indicate a number of the compounds tested showed moderate inhibition of InhA at $50 \mu \mathrm{M}$. Moving from $\mathrm{H}->\mathrm{Me}->^{i} \operatorname{Pr}(\mathbf{3}->\mathbf{5})$ results in increased inhibition, however, the introduction of a ${ }^{t} \mathrm{Bu}(\mathbf{6})$ leads to a significant reduction in enzyme inhibition, suggesting that such a bulky group results in major clashes with the protein. This loosely correlates with the fitness scores, with compound $\mathbf{6}$ showing a lower fitness score than $\mathbf{5}$. The possibility that this region is size sensitive is further supported by the fact that compounds $\mathbf{8 , 1 0}$ and $\mathbf{1 2}$, all of which bear relatively small $\mathrm{R}$ groups, show moderate inhibition. The most potent compound was 2 which showed a total reduction in enzyme activity at $50 \mu \mathrm{M}$. 


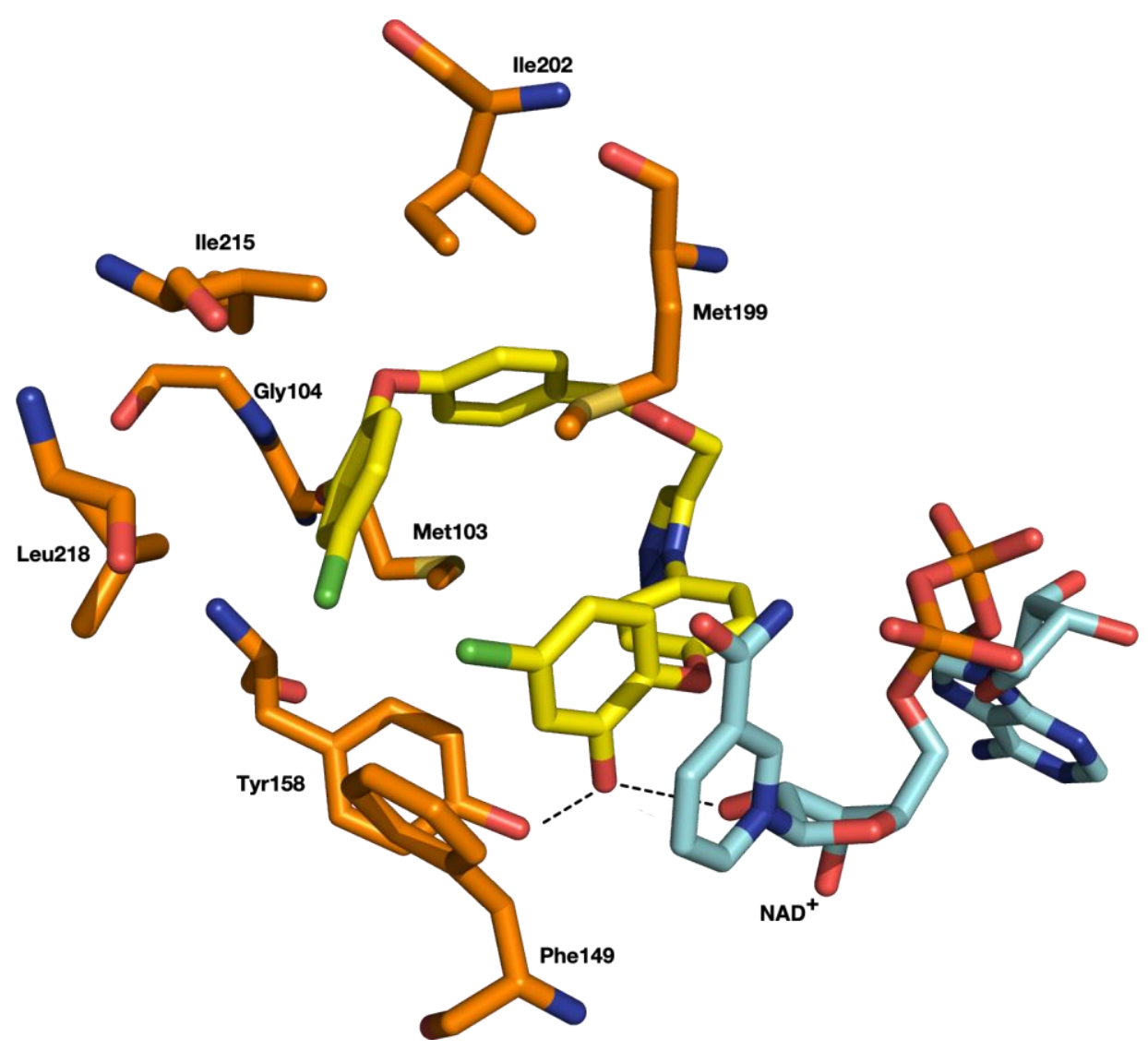

Figure 6. Predicted binding mode for 2. Residues are shown with orange carbons, $N A D^{+}$is shown with teal carbons, 2 is shown with yellow carbons. H-bonds are shown by dashed-black lines. (PDB: 1P45)

The predicted binding mode for $\mathbf{2}$ is shown in Figure 6. This binding pose shows how the 'front' TCS fragment is able to engage the $\mathrm{NAD}^{+}$co-factor and Tyr158 through the key hydrogen bonding network. The 1,5-triazole architecture directs the second TCS fragment back towards the substrate binding loop, where a number of hydrophobic contacts are made. Further evaluation of $\mathbf{2}$ showed it exhibits an $\mathrm{IC}_{50}$ of $5.6 \pm 0.8 \mu \mathrm{M}(\mathrm{n}=3)$. This represents a modest improvement on $\mathrm{TCS}\left(\mathrm{IC}_{50}=\right.$ $9.2 \pm 1.3 \mu \mathrm{M}, \mathrm{n}=3$ ) recorded in experiments conducted in parallel and widely reported in the literature. $^{30}$ 
Whole-cell evaluation of all 12 compounds was undertaken to investigate the correlation between isolated enzyme activity and whole-cell efficiency. Compounds were initially assessed for growth inhibition against Mycobacterium bovis at a fixed concentration of $40 \mu \mathrm{M}$. Results are shown in

\section{Table 2.}

Table 2. Inhibition data for all compounds tested against Mycobacterium bovis at $40 \mu \mathrm{M}$, results are shown as an average of 3 assays.

\begin{tabular}{ccc}
\hline Compound & Inhibition / \% & cLogP \\
\hline $\mathbf{2}$ & 20 & 5.80 \\
$\mathbf{3}$ & 3 & 5.11 \\
$\mathbf{4}$ & -6 & 5.43 \\
$\mathbf{5}$ & 15 & 5.89 \\
$\mathbf{6}$ & 20 & 6.11 \\
$\mathbf{7}$ & 0 & 4.37 \\
$\mathbf{8}$ & 40 & 5.03 \\
$\mathbf{9}$ & 4 & 5.61 \\
$\mathbf{1 0}$ & 19 & 6.09 \\
$\mathbf{1 1}$ & 99 & 6.07 \\
$\mathbf{1 2}$ & 23 & 5.95 \\
TCS & 70 & 4.98 \\
\hline
\end{tabular}

Disappointingly, the isolated assay potency of $\mathbf{2}$ towards InhA did not correlate to whole-cell potency. This could possibly be attributed to inability to pass through the dense mycobacterial cell wall, or other factors such as efficient transport by efflux pumps. ${ }^{31,32}$ It is possible that reintroducing the ortho $\mathrm{Cl}$ atom to the B-ring (giving a compound with a cLogP 6.61) could result in greater whole-cell potency, although the previous QSAR study by Sivaraman et al. ${ }^{24}$ indicate that this chlorine is not critical, this is something that will be explored going forward. Of the 12 
compounds tested, 11 showed the greatest potency, with $99 \%$ growth inhibition at $40 \mu \mathrm{M}$. This compound was subject to further evaluation to determine its $\mathrm{MIC}_{99}$ (Figure 7).

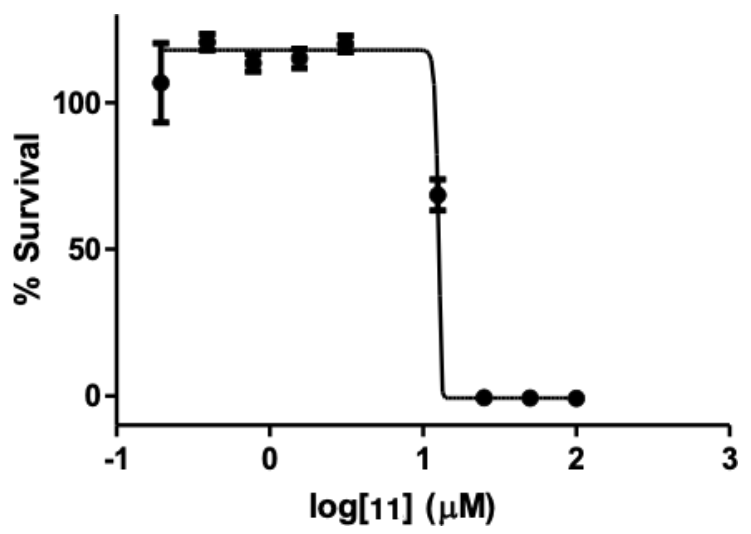

Figure 7. MIC99 curve for 11.

Compound 11 displayed an $\mathrm{MIC}_{99}$ of $12.9 \pm 5.0 \mu \mathrm{M}\left(6.2 \mu \mathrm{g} \mathrm{mL} \mathrm{m}^{-1}, \mathrm{n} .=3\right)$. Clearly there is a disconnect between the activity of $\mathbf{1 1}$ in isolated enzyme assays and its performance in the wholecell screening tests. This suggests that $\mathbf{1 1}$ has other off-target sites within the bacteria which result in significant potency. At high concentrations TCS has been reported to act as a mitochondrial uncoupling, cell membrane permeator and to cause disruption to both lipid and protein biosynthesis. ${ }^{18}$ Further work will be required to elucidate the main biological target(s) of 11.

As previously mentioned, TCS has formed the basis for a number of SAR studies towards potent inhibitors of InhA. The most common modification is replacement of the A-ring $\mathrm{Cl}$ atom with various hydrophobic groups. Comprehensive B-ring modifications remain relatively unexplored. ${ }^{33-35}$ Two examples of previously disclosed direct InhA inhibitors are shown in Figure 8. ${ }^{35,36}$ Compound $\mathbf{2}$ is similar in concept to $\mathbf{3 3}$, recently reported by Rodriguez et al., which sought to merge two TCS molecules in a macrocyclic arrangement. Compounds $\mathbf{3 3}$ and $\mathbf{2}$ have similar $\mathrm{IC}_{50}$ values, which would be expected as they both target the same binding sites. 
<smiles>Oc1cc(Cl)ccc1Oc1ccc(COCc2cnnn2-c2ccc(Oc3ccc(Cl)cc3O)cc2)cc1</smiles>

2

M.W: $550.39 \mathrm{~g} \mathrm{~mol}^{-1}$

$M t b_{\operatorname{lnhA}} \mathrm{IC}_{50}(\mu \mathrm{M}): 5.6 \pm 0.8$

$\mathrm{MIC}_{99}(\mu \mathrm{M}):>80$

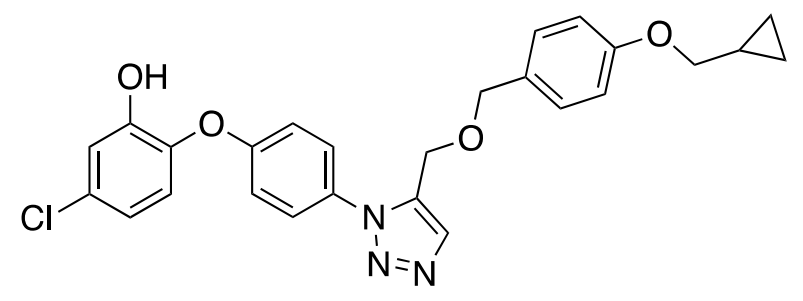

11

M.W: $477.95 \mathrm{~g} \mathrm{~mol}^{-1}$

$M t b_{\text {InhA }} I C_{50}(\mu \mathrm{M}):>50$

$\mathrm{MIC}_{99}(\mu \mathrm{M}): 12.9 \pm 5.0$<smiles>Oc1ccc(CCc2ccc(Oc3ccc(CCc4ccc(Oc5ccc(CCc6cccc(O)c6)cc5)cc4)cc3)cc2)cc1</smiles>

33

M.W: $424.50 \mathrm{~g} \mathrm{~mol}^{-1}$

$M t b_{\operatorname{lnhA}} \mathrm{IC}_{50}(\mu \mathrm{M}): 4.7 \pm 0.4$

$\mathrm{MIC}_{99}(\mu \mathrm{M}): 94.2^{*}$<smiles>[Y10]c1ccc(Oc2ccccc2)c(O)c1</smiles>

34

M.W: $289.43 \mathrm{~g} \mathrm{~mol}^{-1}$

$M t b_{\operatorname{InhA}} \mathrm{IC}_{50}(\mu \mathrm{M}): 0.005 \pm 0.0003$

$\mathrm{MIC}_{99}(\mu \mathrm{M}): 6.6 \pm 1.7$

*Standard deviation not reported by authors

Figure 8. The structures of previously disclosed TCS-based inhibitors of InhA and their biological activities.

In terms of $\mathrm{MIC}_{99}$ data, in this study, 11 showed significant potency in whole-cell assays with an $\mathrm{MIC}_{99}$ value of $12.9 \mu \mathrm{M}$, this value is approaching the $\mathrm{MIC}_{99}$ of $34(6.6 \mu \mathrm{M})$. It is possible that, following the elucidation of 11's target, its potency could be further improved to the match or exceed the activity of $\mathbf{3 4}$. 
The rational in silico design, synthesis and characterization of a novel series of triazole-bearing TCS derivatives is reported. These compounds were designed to exploit the large volume of the InhA active site and occupy both TCS binding sites observed in the PDB: 1P45 crystal structure. Docking results suggested that these compounds would be able to occupy both of the TCS binding regions, possibly giving a direct inhibitor of Mycobacterial InhA with higher affinity and selectivity than TCS. Enzyme assays on purified M. tuberculosis InhA were used to evaluate the compounds synthesized, with the most potent showing an $\mathrm{IC}_{50}$ of $5.6 \pm 0.8 \mu \mathrm{M}$ which is similar to that of TCS. Whole-cell evaluation against M. bovis showed the most potent compound was $\mathbf{1 1}$ which displayed an MIC of $12.9 \pm 5.0 \mu \mathrm{M}$, despite only showing $11 \%$ inhibition at $50 \mu \mathrm{M}$ in isolated enzyme assays.

\section{Associated Content}

\section{Supplementary Information}

Experimental details are reported including: full synthetic procedures and characterization data for all compounds. NMR spectra and analytical HPLC traces of key compounds $\mathbf{2}$ and $\mathbf{1 1}$ are included. Methods for protein expression, purification, isolated enzyme activity assay conditions, $\mathrm{IC}_{50}$ curve for compound $\mathbf{2}$ and whole-cell screening methods are also included.

\section{Author Contributions}

T.A. synthesized all compounds, performed enzyme assays, analysed data and wrote the manuscript. M.L. expressed \& purified InhA and performed enzyme assays. A.L. performed 
whole-cell screening assays and analysed data. L.J.A. supervised the whole-cell screening assays. N.R.T. came up with the initial drug design concept, supervised the synthetic research, contributed to writing and editing the manuscript.

\section{Funding}

T.A. is supported by the Wellcome Trust Antimicrobials and Antimicrobial Resistance (AAMR) doctoral training programme Birmingham/Nottingham [203974/Z/17/A]

M.L. is supported by a Biotechnology and Biological Sciences Research Council doctoral training studentship [Grant Number BB/M008770/1].

A.L. is supported by the Wellcome Trust Antimicrobials and Antimicrobial Resistance (AAMR) doctoral training programme Birmingham/Nottingham [215154/Z/18/Z]

\section{Acknowledgements}

The InhA:pET15a construct was kindly provided by Prof. Peter Tonge (SUNY, Stonybrook, NY, USA). ${ }^{37}$

\footnotetext{
Abbreviations

ETH, ethamobutol; GOLD, Genetic Optimisation for Ligand Docking; HIV, human immunodeficiency virus; HPLC, high-performance liquid chromatography; INH, isoniazid; MDR$\mathrm{TB}$, multi-drug resistant tuberculosis; NAD, nicotinamide adenine dinucleotide (oxidised form); NADH, nicotinamide adenine dinucleotide (reduced form); PZA, pyrazinamide; RIF, rifampicin; RuAAC, ruthenium-catalysed azide alkyne cycloaddition, TB, tuberculosis; TCS, triclosan; XDR$\mathrm{TB}$, extensively drug-resistant tuberculosis
} 


\section{References}

1. $\quad$ World Health Organisation Global Tuberculosis Report; 2019.

2. Bastos, M. L.; Lan, Z.; Menzies, D., An updated systematic review and meta-analysis for treatment of multidrug-resistant tuberculosis. Eur. Respir. J. 2017, 49, 1600803.

3. Günther, G., Multidrug-resistant and extensively drug-resistant tuberculosis: a review of current concepts and future challenges. Clin. Med. (Lond.) 2014, 14, 279-285.

4. Pontali, E.; D'Ambrosio, L.; Centis, R.; Sotgiu, G.; Migliori, G. B., Multidrug-resistant tuberculosis and beyond: an updated analysis of the current evidence on bedaquiline. Eur.

Respir. J. 2017, 49, 1700146.

5. Deoghare, S., Bedaquiline: a new drug approved for treatment of multidrug-resistant tuberculosis. Indian J. Pharmacol. 2013, 45, 536-7.

6. Xavier, A.; Lakshmanan, M., Delamanid: A new armor in combating drug-resistant tuberculosis. J. Pharmacol. Pharmacother. 2014, 5, 222-224.

7. Zhai, W.; Wu, F.; Zhang, Y.; Fu, Y.; Liu, Z., The Immune Escape Mechanisms of Mycobacterium Tuberculosis. Int J Mol Sci 2019, 20, 340.

8. Marrakchi, H.; Laneelle, G.; Quemard, A. K., InhA, a target of the antituberculous drug isoniazid, is involved in a mycobacterial fatty acid elongation system, FAS-II. Microbiology 2000, 146, 289-296.

9. Rozwarski, D. A.; Grant, G. A.; Barton, D. H.; Jacobs, W. R., Jr.; Sacchettini, J. C., Modification of the NADH of the isoniazid target (InhA) from Mycobacterium tuberculosis. Science 1998, 279, 98-102.

10. Timmins, G. S.; Deretic, V., Mechanisms of action of isoniazid. Mol. Microbiol. 2006, $62,1220-7$.

11. Zhang, Y.; Heym, B.; Allen, B.; Young, D.; Cole, S., The catalase-peroxidase gene and isoniazid resistance of Mycobacterium tuberculosis. Nature 1992, 358, 591-593.

12. Zhao, X.; Yu, H.; Yu, S.; Wang, F.; Sacchettini, J. C.; Magliozzo, R. S., Hydrogen Peroxide-Mediated Isoniazid Activation Catalyzed by Mycobacterium tuberculosis

Catalase-Peroxidase (KatG) and Its S315T Mutant. Biochemistry 2006, 45, 4131-4140.

13. Manjunatha, U. H.; S Rao, S. P.; Kondreddi, R. R.; Noble, C. G.; Camacho, L. R.; Tan, B. H.; Ng, S. H.; Ng, P. S.; Ma, N. L.; Lakshminarayana, S. B.; Herve, M.; Barnes, S. W.; Yu, W.; Kuhen, K.; Blasco, F.; Beer, D.; Walker, J. R.; Tonge, P. J.; Glynne, R.; Smith, P. W.; Diagana, T. T., Direct inhibitors of InhA are active against Mycobacterium tuberculosis. Sci. Transl. Med. 2015, 7, 269ra3-269ra3.

14. Martínez-Hoyos, M.; Perez-Herran, E.; Gulten, G.; Encinas, L.; Álvarez-Gómez, D.; Alvarez, E.; Ferrer-Bazaga, S.; García-Pérez, A.; Ortega, F.; Angulo-Barturen, I.; RullasTrincado, J.; Blanco Ruano, D.; Torres, P.; Castañeda, P.; Huss, S.; Fernández Menéndez, R.; González del Valle, S.; Ballell, L.; Barros, D.; Modha, S.; Dhar, N.; Signorino-Gelo, F.; McKinney, J. D.; García-Bustos, J. F.; Lavandera, J. L.; Sacchettini, J. C.; Jimenez, M. S.; Martín-Casabona, N.; Castro-Pichel, J.; Mendoza-Losana, A., Antitubercular drugs for an old target: GSK693 as a promising InhA direct inhibitor. EBioMedicine 2016, 8, 291-301.

15. Rozman, K.; Sosic, I.; Fernandez, R.; Young, R. J.; Mendoza, A.; Gobec, S.; Encinas, L., A new 'golden age' for the antitubercular target InhA. Drug Discov. Today 2017, 22, 492-502. 
16. Chetty, S.; Ramesh, M.; Singh-Pillay, A.; Soliman, M. E., Recent advancements in the development of anti-tuberculosis drugs. Bioorg. Med. Chem. Lett. 2017, 27, 370-386.

17. Parikh, S. L.; Xiao, G.; Tonge, P. J., Inhibition of InhA, the Enoyl Reductase from Mycobacterium tuberculosis, by Triclosan and Isoniazid. Biochemistry 2000, 39, 7645-7650.

18. Vosatka, R.; Kratky, M.; Vinsova, J., Triclosan and its derivatives as antimycobacterial active agents. Eur. J. Pharm. Sci. 2018, 114, 318-331.

19. Kuo, M. R.; Morbidoni, H. R.; Alland, D.; Sneddon, S. F.; Gourlie, B. B.; Staveski, M. M.; Leonard, M.; Gregory, J. S.; Janjigian, A. D.; Yee, C.; Musser, J. M.; Kreiswirth, B.; Iwamoto, H.; Perozzo, R.; Jacobs, W. R., Jr.; Sacchettini, J. C.; Fidock, D. A., Targeting tuberculosis and malaria through inhibition of Enoyl reductase: compound activity and structural data. J. Biol. Chem. 2003, 278, 20851-9.

20. Jones, G.; Willett, P.; Glen, R. C.; Leach, A. R.; Taylor, R., Development and validation of a genetic algorithm for flexible docking. J Mol Biol 1997, 267, 727-48.

21. Shirude, P. S.; Madhavapeddi, P.; Naik, M.; Murugan, K.; Shinde, V.; Nandishaiah, R.; Bhat, J.; Kumar, A.; Hameed, S.; Holdgate, G.; Davies, G.; McMiken, H.; Hegde, N.; Ambady, A.; Venkatraman, J.; Panda, M.; Bandodkar, B.; Sambandamurthy, V. K.; Read, J. A., Methyl-Thiazoles: A Novel Mode of Inhibition with the Potential to Develop Novel Inhibitors Targeting InhA in Mycobacterium tuberculosis. J. Med. Chem. 2013, 56, 8533-8542. 22. Ng, P. S.; Manjunatha, U. H.; Rao, S. P. S.; Camacho, L. R.; Ma, N. L.; Herve, M.; Noble, C. G.; Goh, A.; Peukert, S.; Diagana, T. T.; Smith, P. W.; Kondreddi, R. R., Structure activity relationships of 4-hydroxy-2-pyridones: A novel class of antituberculosis agents. Eur. $J$. Med. Chem. 2015, 106, 144-156.

23. Encinas, L.; O’Keefe, H.; Neu, M.; Remuiñán, M. J.; Patel, A. M.; Guardia, A.; Davie, C. P.; Pérez-Macías, N.; Yang, H.; Convery, M. A.; Messer, J. A.; Pérez-Herrán, E.; Centrella, P. A.; Álvarez-Gómez, D.; Clark, M. A.; Huss, S.; O’Donovan, G. K.; OrtegaMuro, F.; McDowell, W.; Castañeda, P.; Arico-Muendel, C. C.; Pajk, S.; Rullás, J.; AnguloBarturen, I.; Álvarez-Ruíz, E.; Mendoza-Losana, A.; Ballell Pages, L.; Castro-Pichel, J.; Evindar, G., Encoded Library Technology as a Source of Hits for the Discovery and Lead Optimization of a Potent and Selective Class of Bactericidal Direct Inhibitors of Mycobacterium tuberculosis InhA. J. Med. Chem. 2014, 57, 1276-1288.

24. Sivaraman, S.; Sullivan, T. J.; Johnson, F.; Novichenok, P.; Cui, G.; Simmerling, C.; Tonge, P. J., Inhibition of the bacterial enoyl reductase FabI by triclosan: a structure-reactivity analysis of FabI inhibition by triclosan analogues. $J$. Med. Chem. 2004, 47, 509-18.

25. Barral, K.; Moorhouse, A. D.; Moses, J. E., Efficient Conversion of Aromatic Amines into Azides: A One-Pot Synthesis of Triazole Linkages. Org. Lett. 2007, 9, 1809-1811.

26. Boren, B. C.; Narayan, S.; Rasmussen, L. K.; Zhang, L.; Zhao, H.; Lin, Z.; Jia, G.; Fokin, V. V., Ruthenium-Catalyzed Azide-Alkyne Cycloaddition: Scope and Mechanism. J. Am. Chem. Soc. 2008, 130, 8923-8930.

27. Johansson, J. R.; Beke-Somfai, T.; Said Stålsmeden, A.; Kann, N., RutheniumCatalyzed Azide Alkyne Cycloaddition Reaction: Scope, Mechanism, and Applications. Chem. Rev. 2016, 116, 14726-14768.

28. Creary, X.; Anderson, A.; Brophy, C.; Crowell, F.; Funk, Z., Method for Assigning Structure of 1,2,3-Triazoles. J. Org. Chem. 2012, 77, 8756-8761.

29. He, X.; Alian, A.; Stroud, R.; Ortiz de Montellano, P. R., Pyrrolidine carboxamides as a novel class of inhibitors of enoyl acyl carrier protein reductase from Mycobacterium tuberculosis. J. Med. Chem. 2006, 49, 6308-23. 
30. Slepikas, L.; Chiriano, G.; Perozzo, R.; Tardy, S.; Kranjc, A.; Patthey-Vuadens, O.; Ouertatani-Sakouhi, H.; Kicka, S.; Harrison, C. F.; Scrignari, T.; Perron, K.; Hilbi, H.;

Soldati, T.; Cosson, P.; Tarasevicius, E.; Scapozza, L., In Silico Driven Design and Synthesis of Rhodanine Derivatives as Novel Antibacterials Targeting the Enoyl Reductase InhA. J. Med. Chem. 2016, 59, 10917-10928.

31. Szumowski, J. D.; Adams, K. N.; Edelstein, P. H.; Ramakrishnan, L., Antimicrobial efflux pumps and Mycobacterium tuberculosis drug tolerance: evolutionary considerations. Curr. Top. Microbiol. Immunol. 2013, 374, 81-108.

32. Balganesh, M.; Dinesh, N.; Sharma, S.; Kuruppath, S.; Nair, A. V.; Sharma, U., Efflux Pumps of Mycobacterium tuberculosis Play a Significant Role in Antituberculosis Activity of Potential Drug Candidates. Antimicrob. Agents Chemother. 2012, 56, 2643-2651.

33. He, X.; Alian, A.; Ortiz de Montellano, P. R., Inhibition of the Mycobacterium tuberculosis enoyl acyl carrier protein reductase InhA by arylamides. Bioorg. Med. Chem. 2007, $15,6649-6658$.

34. Stec, J.; Vilchèze, C.; Lun, S.; Perryman, A. L.; Wang, X.; Freundlich, J. S.; Bishai, W.; Jacobs Jr., W. R.; Kozikowski, A. P., Biological Evaluation of Potent Triclosan-Derived Inhibitors of the Enoyl-Acyl Carrier Protein Reductase InhA in Drug-Sensitive and DrugResistant Strains of Mycobacterium tuberculosis. ChemMedChem 2014, 9, 2528-2537.

35. Sullivan, T. J.; Truglio, J. J.; Boyne, M. E.; Novichenok, P.; Zhang, X.; Stratton, C. F.; Li, H. J.; Kaur, T.; Amin, A.; Johnson, F.; Slayden, R. A.; Kisker, C.; Tonge, P. J., High affinity InhA inhibitors with activity against drug-resistant strains of Mycobacterium tuberculosis. ACS Chem. Biol. 2006, 1, 43-53.

36. Rodriguez, F.; Saffon, N.; Sammartino, J. C.; Degiacomi, G.; Pasca, M. R.; Lherbet, C., First triclosan-based macrocyclic inhibitors of InhA enzyme. Bioorg. Chem. 2020, 95, 103498.

37. Parikh, S.; Moynihan, D. P.; Xiao, G.; Tonge, P. J., Roles of tyrosine 158 and lysine 165 in the catalytic mechanism of InhA, the enoyl-ACP reductase from Mycobacterium tuberculosis. Biochemistry 1999, 38, 13623-34.

\section{Table of Contents Graphic}

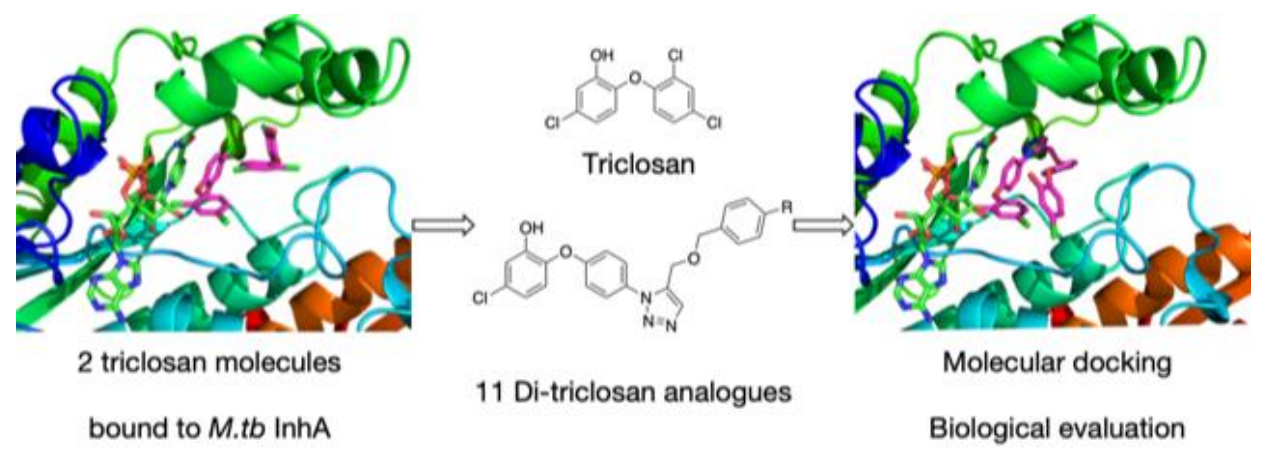

